\title{
Focusing on artisanal fleets in a new scenario: The case of Andalusia (Spain)
}

\section{David Florido del Corral*}

Research Group for Socio-Cultural Identities Studies in Andalusia, Department of Social Anthropology, University of Seville Received 28 January 2008; received in revised form 7 February 2008; accepted 7 February 2008

\begin{abstract}
This paper analyses how artisanal fleets in the South Atlantic Coast of Spain (Andalusia) are transformed at the macro-level by political and economic processes. The article will first describe the web of economic and political dynamics, and it will then outline several socioeconomic and cultural patterns of artisanal fleets, examining strategies that are used to encourage commercial specialisation, technological innovation, capitalisation and productive intensification. The resulting social conflict is also examined. From such a study, this essay intends to promote a theoretical debate concerning the importance of new conceptions of artisanal fishing today, a time when local and global processes are highly interconnected.
\end{abstract}

(C) 2008 Elsevier Ltd. All rights reserved.

Keywords: Anthropology of fishing; Artisanal fishing; Globalisation/localisation; Andalusia; Spain

\section{Introduction}

The findings presented in this paper are the result of a $\mathrm{PhD}$ thesis. ${ }^{1}$ The purpose of this paper is to highlight one process, artisanalisation, that is highly relevant to Andalusian fisheries today [1]. This analysis is based on a series of conventional statistical variables: whereas many others have focused on the decrease in the number of vessels and workers as well as the decline of fleet capacity of artisanal fisheries, the purpose here is to emphasise a remarkable growth of power in this segment. ${ }^{2}$ That is, there is an overall process consisting of power and workforce use

\footnotetext{
${ }^{*}$ Tel.: + 34 954556944; fax: +34954551384 .

E-mail address: dflorido@us.es

${ }^{1}$ The title of the thesis is: State, Associations and Local Power in the Configuration of the Fisheries Policy (in Spanish). It is based on the case studies of Barbate and Conil de la Frontera, located in the area of the Straits of Gibraltar. Ethnographic references of this essay are applied primarily to these two towns.

${ }^{2}$ Between 1975 and 2005, the number of vessels of the artisanal fleet has decreased from 2113 to 1883 units $(-10.9 \%)$; tonnage - GRT-has decreased from 45,668 to $28,403(-37.8 \%)$; workers, from 16,068 to $10,063(-37.3 \%)$. Power, however, has increased from 190,471 HP to 233,336 HP $(22 \%$ !). (Own drafting, based on data from the Directorate General of Fisheries and Aquaculture of Andalusia).
}

intensification that does not fit into the parameters assigned to the artisanal model. In the artisanal category, both the artisanal or small scale (exclusive in ports such as Conil or Tarifa), and the so-called coastal or shallow-water fleets (prevailing in Isla Cristina, Punta Umbría, Sanlúcar de Barrameda, Puerto de Santa María, Barbate or Algeciras) are included (Fig. 1). These share features such as: management and ownership systems that are based on familial ties; (soft) hierarchical links between skipper and sailors; remuneration system (named as a la parte); amounts of time spent on fishing trips; (low) ratios of productivity [2] and positions of productive units within the fisheries chain (Table 1). Technically, artisanal fisheries in Andalusia are represented by a wide set of fishing gear types: bottom trawling, seine nets, longlines (coastal fleets), and a very miscellaneous group of small-scale gear types, which include: drag lines, bottom longlines, trammel nets, drags, pitcher traps, traps, hand jigs and others. ${ }^{3}$

Globally, this artisanalisation coincides with the near disappearance of industrial-scale high sea fleets that formerly fished in international waters. In particular, such artisanalisation is connected to the cessation of activities of

\footnotetext{
${ }^{3}$ Besides, it is to take into account the tuna trap fishing, but its parameters are different.
} 


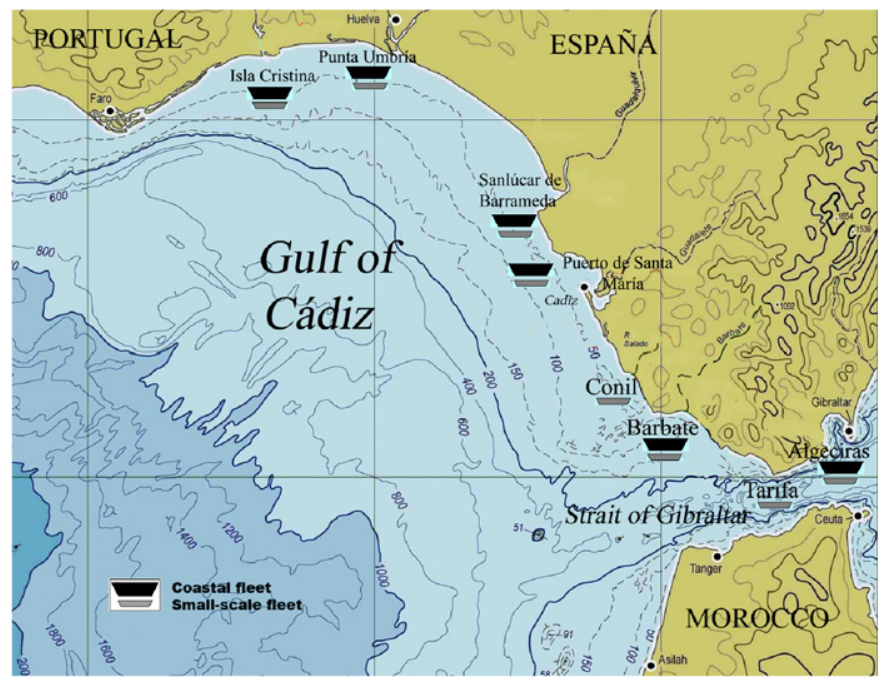

Fig. 1. Main fishing ports on the South Atlantic Coast of Spain (Western Andalusia, Strait of Gibraltar).

medium range vessels, which had historically operated along the north-western shores of Africa as far down as the Saharan bank. It is especially important to note the historic roles of different types of fleets (the purse seiners, the shrimp trawlers and the longliners, which are based in Atlantic and Mediterranean ports) that stopped fishing when the EU-Morocco fishing agreement was blocked (1999-2006). Indeed, part of this fleet, far from being broken up by the financial support mechanisms of the Common Fisheries Policy (CFP), has been redeployed to Spanish jurisdictional waters, both in the Atlantic and in the Mediterranean, so that the Regional Government is now considering it as an artisanal fleet. In fact, this process is not exclusive to the Spanish coasts; for small-scale fishermen have retained their social, cultural and economic weight throughout the world to such an extent that there are more artisanal fishermen today than there has ever been before [3]. Artisanal fleets both provide greater job opportunities to coastal peoples than do large-scale vessels and also allow sailors to become ship owners [4], which is more meaningful to them.

As Van Ginkel [5] has pointed out, due to the high density of economic and political flows that cross local territories and societies, it is not possible anymore (if it ever was viable) to design a scientific approach that does not integrate local and supra-local social processes. Methodological approaches must both go beyond understanding global/local relations in terms of mere reaction or opposition and overcome this reification exercise that associates global to complexity, conflict and heterogeneity, while understanding local in the opposite terms. It is instead a question of avoiding the mystifying idea of "globalism," according to which modernity is precisely characterised by a loss of territorial character of economic, political, social and cultural processes in general. García Canclini [6] has unmasked the metaphor of globalisation as a "diffuse process" without territorial anchorage. On the
Table 1

Traditional and current characteristics of the (Andalusian) artisanal fleets: comparative outlook

Conventional pattern of artisanal Proposal for a new concept of fisheries artisanal fisheries

The ship owner works on board and The ship owner works on board, but the technical and social relationships the relationships are hierarchical are, more or less, egalitarian. Weak

hierarchical ties in social and technical relations of production

The company is family owned and The company is family owned and managed: kinship is the structure of managed: kinship is the reinforced capitalisation and of labour system structure of capitalisation and of labour system, and the participation of other sailors generates conflicts

Linked to household economy Linked to household economy, as well as to global and regional economic trends

Subsistence-oriented fishery Subsistence/household oriented, but severely affected by commercial dynamics and social reproduction through plenty of insertions within market economy

Crew per vessel: 2-4 (small-scale fleet), 7-18 (coastal fleet)

Fewer workers/vessel, but trends to worsening of job conditions: employment of immigrants as workforce

Pre-modern property and profit sharing system (a la parte)

Pre-modern property and profit sharing system (a la parte) reinforced, and the partnership of property more focused on family strategies

Extractive effort low (days per week, Intensification of extractive effort in distance and depth of fishing grounds, duration of fishing voyages, number and size of fishing intensive

gears, average age of fleets...)

Diversity of fishing gears and variety Specialisation in fewer fishing gears of targeted species and targeted species, with respect to global commercial trends

Technologies underdeveloped. Capitalisation low

Increasing investments for installation of new technologies and fishing gears to intensify the fishing effort

Fishing strategies adapted to local Fishing strategies adapted to global environmental trends and local commercial and political trends

Weak position in fisheries chain and Weak position in fisheries chain and within the political arrangement

within political arrangement, but reinforcement of artisanal fishery as a political subject

Source: own drafting.

contrary, globalisation should be understood as being implemented by socio-political agents and its rationale as being based on strong political steering of economic flows. Consequently, a glocal approach for a critical analysis of artisanal fisheries in present time is claimed. ${ }^{4}$

The main issue of concern for researchers of artisanal fisheries has been either the impact of fisheries on resources

${ }^{4}$ The neologism, "glocalisation," appeared first in the work of

Robertson [7]. 
1 or issues of management [3,8]; this study, however, is more interested in the social and economic dimensions of 3 Q1 artisanal fleets $[4,9,10]$. Specifically, this article examines the role of artisanal fleets and their social and cultural reproduction chances [11-13], ${ }^{5}$ as well as changes in social identity of fishermen in their current economic and political contexts. With regard to this, it is worth mentioning that in their political and discursive strategies, fishermen articulate their core identity through references to traditional dimensions (reproduced throughout history, transmitted silently from generation to generation) and the artisanal dimension (relying on the vernacular know-how in very specific cultural frameworks) of fish catching and processing.

\section{Global processes affecting artisanal fleets}

Within the contemporary framework of economic and political globalisation, economic regionalisation processes can be seen in the following activities: creation of new fish markets, new decision-making concentration, dynamics of new technology within the Union and development of new narratives and discourses on fisheries and fishermen (new environmental and commercial criteria, new business organisation and production schemes, or the fortress of productive unit competitiveness...). Fisheries in southern European waters are being influenced by global dynamics of dissimilar categories and scale, but the common rule of the last three decades of fisheries' policy is the application of market guidelines. The European Commission has been the main political actor in this process. A proper example is the decline of European fishing activities in Africa. Thus one should consider the European Mediterranean Policy as a regionalisation reference and analyse the geo-strategic framework of relations between the European Union and Morocco [15]. The European Union policy in northern Africa focuses mainly on merely commercial objectives [16], and within this context, the renewal of fishing agreement between Morocco and the EU did not make economic sense. On the other hand, Andalusia obtains its supply mainly from the Maghreb area ( $41 \%$ of the total), followed by other EU members $(28 \%)^{6}{ }^{6}$ It is the Andalusian harvesting sector producers who face the consequences of these macro-regional processes. ${ }^{7}$

\footnotetext{
${ }^{5}$ According to the latter [13, p. 136], fishermen are becoming an "economic actor, integrated into vertical food system, and cast merely as a commodity producer or supplier of raw materials, without any real powers of negotiation and held firmly in place by the administrative system". On the imprint of these processes on fishermen's identity and social prestige, see $[6,14]$.

${ }^{6}$ Source: Directorate General of Fisheries and Aquaculture of Andalusia, 2002 data.

${ }^{7}$ Thus, fishing products rank first in the list of imports from Morocco over the last 5-year period, both for Andalusia and for Spain, and show significant increases between 1998 and 2001, reflecting the changes occurred since Spanish vessels have stopped fishing there (1999). For Spain, in million euros: 1998: 81; 1999: 187; 2000: 271; 2001: 320. For
}

The CFP was another policy with a formally political character that structurally conditioned the recent evolution of Andalusian artisanal fleets by combining financial tools (Financial Instrument for Fisheries Guidance, FIFG, basically 1995-2006) and political tools (a legal corpus of guidelines, documents and regulations). This was a political construct structured into different action lines (resources, structures, marketing and agreements with third countries), whose explicit purpose is managing, controlling and guiding the whole value chain of fisheries, from production to marketing, in order to set up a regional market for fish in Europe. The political aim of the CFP was reduction of harvesting sector, an objective that has appeared recurrently in EU documents since 1990. The fact that the Commission has exclusive control in resource policy gives us an idea of the commanding character of this political instrument [17]. The structural policy was originally designed to address a substantial part of the economic reorientation costs and social consequences resulting from partial dismantling of the European fishing sector; the case of Andalusia, however, evidences that structural funds have become a major factor indicating the formidable technological renovation process that has taken place in the Andalusian artisanal fleet. ${ }^{8}$ The result of application of structural aids to artisanal Andalusian fleets is that there are fewer vessels, but those vessels have a higher fishing capacity. To summarise, the current economic and social situation of Andalusian fisheries cannot be understood without taking into account the participation of public funds in the capitalisation of vessels: European structural funds and, in the case of Andalusia, the Modernisation Plan of the Andalusian Fishing Sector, started in 1997. It is not surprising therefore that the documents of the Commission that examine the redesign of the CFP, such as the Green Paper [18], openly recognise the failure of tonnage reduction objectives. Furthermore, the European Commission has accounted for reduction in fishing effort in terms of number of productive units and tonnage, overlooking the real fishing capacity resulting from mechanisation and technological innovation. This was another of the Commission's objectives, to achieve a modern and competitive fleet.

Last, but not least, it is to consider the exponential growth of commercial flows of fish productions that play a

$\overline{\text { (footnote continued) }}$

Andalusia, in million euros: 1998: 81; 1999: 80; 2000: 116; 2001: 120. Source: ICEX (Spanish Foreign Trade Institute)

${ }^{8}$ Around $70 \%$ of the small boat fleet in Conil has been renovated, by either new constructions or partial refurbishments. It was necessary to wait until the application of the FIFG was regulated (EC Regulation 3699/93) to appraise the results of the CFP in the capitalisation of Conil's fleet, since prior to that date vessels less than $9 \mathrm{~m}$ long were excluded from the structural policy for modernisation. In Barbate, figures reach almost $90 \%$ of the vessels in the different categories; however, this total figure includes a share of breaking ups $(25 \%)$ as the direct result of the crisis of the Moroccan fishing grounds in the last years. Source: own, produced with data from the Directorate General of Fisheries and Aquaculture of the Regional Government of Andalusia. 
1 central role in this context. One of the implicit objectives of the CFP, as the data confirm, is to increase commercial flows, especially imports of production from out of the European Union. ${ }^{9}$ This has resulted in the generation of an extraordinary commercial business, in which the space of Andalusian harvesting sector has been challenged and questioned. In order to understand this new scenario, it is important to take into account that the average value of a ton of imported fish is double that of a ton produced in the EU. This trend is even more significant when one considers the socioeconomic processes such a trend brings about, such as the emergence of new commercial agents and the displacement of some of the pre-existing trading networks. The question is therefore to find out how the new global context is affecting the structure of commercial relations in Andalusia and in Spain. Thus, to sum up, artisanal fleets are facing an intensification of imports and number of transactions as a result of commercial liberalisation, including integration of marketing agents in increasingly hierarchical networks that are more and more controlled by major companies, penetration of large food companies or large commercial chains in the fish market, creation of commercial hubs for "second sales," opening of large food distribution warehouses supplied by important wholesalers operating independently from the traditional channels and formation of a new demand based on processed and frozen products.

If one considers the typical characteristics of fish markets in Andalusia [19], ${ }^{10}$ the traditionally dependent position of fishermen as raw material suppliers may be reinforced in an economic chain that is politically foreign to them. In order to express the new "glocal" reality of fish product markets in Andalusia in figures, one should first highlight the decrease of first sale prices over the past 15 years, a process that becomes more significant if the increase in production costs is considered - due to the already mentioned capital intensification process, increased costs, evolution of fuel prices, overall inflation, etc. The port of Barbate is an accurate example of this stagnation process. ${ }^{11}$ It is, however, necessary to point out that the situations of the local Andalusian fleets are not homogeneous; some fresh

\footnotetext{
${ }^{9}$ The data for the 1990s are indeed spectacular: between 1989 and 1998, EU imports increased by $16 \%$ in tonnage and by $74 \%$ in value. The trade balance experienced a negative evolution along the same parameters: $-14 \%$ in tonnage and $-88 \%$ in value [19].

${ }^{10}$ To mention some of these characteristics: poor structural connection between extractive and commercial sectors, with greater pricing power of the latter, opaque price formation, oligopolistic practices in final markets (merca network), whose operators establish hierarchical relationships with port marketing agents. A further distinctive fact is the poor knowledge of commercial channels by ship owners. This has resulted in oligopolistic demand practices in the first sale, with a high concentration of transactions by a few operators.

${ }^{11}$ In Barbate, they are predominantly pelagic species with traditionally massive catches. The evolution of average price in current euros has been as follows: 0.87 (1985), 1.07 (1990), 1.14 (1995), 1.17 (2000), 1.48 (2004). Source: Directorate General of Fisheries and Aquaculture of the Regional Government of Andalusia. If prices are adjusted to inflation using constant values, the result is a decrease of almost $43 \%$ [19].
}

fish producers have been able to gain remarkably solid strongholds in regional national and even international markets. In this respect, the case of Conil is paradigmatic, since it has achieved the highest average price of all the Andalusian fresh fish productions since the 1990s, exceeding $6 € / \mathrm{kg}$ in $2004 .{ }^{12}$ This is because the catches of Conil are highly valued by restaurants. This example indicates that it is possible to expand some productions that achieve high market values, since their artisanal character is an identification element that adds value to fish production.

\section{Socioeconomic challenges of artisanal fleets}

It is necessary to underline the paradoxical and contradictory character of articulation of artisanal fleets in the global context outlined above. The analytical focus of this paper will be to discover how vernacular cultural forms that are connected to socioeconomic organisation are maintained, displaced or changed within the framework of the new political economy. Although the artisanal model has been preserved, changed and even reinforced in some regions, its permanence is full of tensions and imbalances; this is what we intend to show below.

\subsection{Commercial specialisation}

Spanish artisanal fisheries are characterised by their multi-species and multi-gear strategies. Nevertheless, many of the fleets that fish in this area are very selective and species specific, targeting either a single species or a limited group of species [20]. In other words, although fisheries as a whole show high multi-specificity, this is currently sustained by a few species of high commercial value [21]. This specialisation may be partially considered as a consequence of spatial extension of marketing operations, so that trading nets provide an incentive for fishing of species that had formerly not been commercially valued in local and regional contexts or, if caught, were used for home consumption. Thus, the policy aimed at opening new markets favours new productive maximisation strategies in general. The example of intensive fishing of octopus by the fleets of Barbate and Conil is one of the most significant local expressions of this process, ${ }^{13}$ which has led to a new specialised fishing gear being developed, the so-called pulperas (hand jigs), instead of more traditional gear types. ${ }^{14}$

From the perspective of local fishermen, the reorientation of economic strategies to these fisheries does not

\footnotetext{
${ }^{12}$ The evolution of average price has been: 2.70 (1985); 4.30 (1990); 4.48 (1995); 3.34 (2000); 6.28 (2004). Source: Directorate General of Fisheries and Aquaculture of the Regional Government of Andalusia.

${ }^{13}$ Other significant examples of the Atlantic Andalusian fleets are the fishing of black spot (or red) sea bream in the Straits of Gibraltar using sea-bottom long lines; or the fishing of Striped Venus, with hydraulic dredges in the coast of Huelva [22].

${ }^{14}$ It is a gear made up of two crowns of hooks with sinkers, in which bait (salted sardine) is placed to attract this voracious mollusk.
} 
1 depend as much on an increased demand, as it depends on more favourable labour and redistribution conditions. Octopus is an arrival species (that is, that arrives at the coast seasonally), which is not fished in remote grounds. This facilitates fishing operations and reduces their cost; fishing with pulperas costs less than it does with other gears, especially longlines and gillnets and it is easy for fishermen to use them. As compared to fishing with other techniques, working hours are lesser, although they do involve a greater fishing effort. When there is octopus, the maximisation strategy requires a higher number of crew members (numbers rise from two/three to four/five). As prices have remained stable because of the price control strategies of marketing agents, each fisherman can calculate the effort needed to make the fishing runs cost effective. In conclusion, octopus enhances the industry's activity, and fishermen perceive that, in less harsh conditions, they can achieve reasonable outcomes.

Nevertheless, the cost effectiveness of mass capture fisheries such as octopus can be achieved only with a very high exploitation rate, so that octopus seasons may result in seasonal exhaustion of catches [22]. Fishermen used to justify this circumstance, by noting that octopus is a "seasonal species;" that is, they are using the environmental argument to explain the evolution of the resource, whereas such a process is, in reality, more the result of productive maximisation practices. Regardless, local management measures and tools that are focused on octopus have been implemented [23]; what is important to understand is the medium-term sustainability of the model in bio-socioeconomic terms: the economic success of fishermen always depends on a high exploitation rate, even to such an extent that fishing grounds are exploited intensively. This is the significance of mercantilisation of artisanal productions, which in some cases is not even questioned by some producers or politicians.

A more recent example in the southern ports is the socalled pez sable [trichiurus lepturus], which has been the subject of a new episode of productive specialisation since 2001. The development of these fisheries can be explained by the fact that it is a staple species of daily fish consumption in southern Portugal to such an extent that the demand it generates must be supplied from the port fish market of Barbate by mean of small boats that come from Algeciras and Conil that fish by using sea-bottom longlines (baited with salted sardines or mackerels). The profitability of these catches has attracted the attention of Barbate's fishermen, who have refurbished some of their smaller purse seiners and trawlers to adapt them to the needs of fishing of this species. In order to ensure vessels from the three ports with access in equal conditions to fishing grounds, a territorial demarcation system has been established. This demarcation system provides access in turns to the identified fishing grounds and regulates fishing times.

In short, the most significant event in this past decade is the spreading of specialisation processes to artisanal gears and techniques. As a consequence of this, these fleets are abandoning one of the long-time features of the artisanal model, which included seasonal productive diversification as a means of adapting to the ecosystem. Therefore, the commercial specialisation process has deep impacts on fish production systems at different levels; it is an incentive for some technical and territorial strategies that are promoted to the detriment of others, it encourages onset of new modalities, and it even generates new ways of perceiving economic returns of fishing activities. Hence, in Conil, the drop of production in 2001 of one of the most fished species, the red mullet, has been perceived in terms of a fishing grounds crisis, despite the fact that for other species, catching figures have remained stable or increased.

\subsection{Technological innovation, capitalisation and productive intensification}

Andalusian fleets have made an impressive ship capitalisation effort and one of its most evident outcomes has been the refurbishment of vessels and introduction of new equipments. As late as 2000-2006, when the fleet formerly operating in Morocco was already paralysed, the distribution of structural aids to the Andalusian fishing sector evidences the concentration of investment and strategic efforts of ship owners in maintaining and improving their vessels. Thus, more than $50 \%$ of the submitted projects involved new construction and modernisation of vessels, whilst the funds dedicated to breaking ups represented scarcely $2 \%$ of the whole. ${ }^{15}$ When analysing this, the elements that underpin the patterns of the labour culture of fisheries in Andalusia have to be kept in mind [24]. ${ }^{16}$ First, knowledge applied to productive processes that have historically been generated and reproduced must be understood as a primary factor for controlling fishing effort rates. An important element is the relationship of this experience-based knowledge with new forms of territorial uses and new resources provided by new navigation devices: GPS, sounders, sonar and especially plotters. The new possibilities opened by these instruments for new knowledge concerning the environment have not

\footnotetext{
${ }^{15}$ The distribution of FIFG aids for Andalusia along this period has been: type 1 (Scrapping of vessels): $1.9 \%$; type 2 (Fleet renewal or Modernisation of fishing vessels): 53.6\%; type 3 (Protection and development of aquatic resources, Fishing port facilities, Development of aquaculture, Processing and marketing of fishery and aquaculture products) $30.2 \%$; 4 (Small-scale coastal fishing, Measures to identify and promote new market outlets, Social measures accompanying restructuring, Measures by groups within the trade): $11.5 \% 5$ (Technical assistance: $2.6 \%)$. Source: Directorate General of Fisheries and Aquaculture of Andalusia.

${ }^{16}$ Applied to fisheries, this concept attempts to integrate the multiple dimensions of work in the sea, covering not only labour processes in their social, technological, knowledge and cosmovision dimensions, but also household organisation practices, sociability patterns, institutionalised local management forms, historical processes of relationships with institutional structures such as the government or the market, etc.
} 
1 displaced vernacular forms of knowledge [25], since the latter are still fully operational.

Second, the adoption of a new business rationale, highly determined by objectives typical of a commercial system, does not cancel out other cultural patterns that are linked to organisation of family groups and to reproduction of vessels. If one must underline an institution of artisanal fishing culture that stimulates the intensification strategy, this is the aparceria (partnership), which can be understood both in terms of distribution of outcomes/profits between ship owners and sailors as well as in terms of organisation of property. ${ }^{17}$ Thus, the ownership system has undergone substantial changes in recent decades; the historical system between owners and captains is being replaced by a more static system in which ship captains are becoming the sole owners of vessels, with the intent to pass their vessels on to their descendants. This new standard, which makes sense from the household economy perspective, is a new factor that may help to explain the fact that ships are maintained in an economic recession context. Therefore, the recent formula, "son of the ship owner/captain on board," is an expression of a more stable group of ship owners who have linked the capital reproduction rationale to the rationale of family reproduction.

In Conil, there is a parallel process to the fleet's capitalisation. The underlying dynamics is the access of former fishermen from Conil (and their descendants through them) that had traditionally sailed in "foreign" fleets (such as Barbate, Cádiz or Puerto de Santa María) to the ownership of small vessels, once public capital (European Structural Aids) has allowed them to undertake the corresponding investments. Thus, the arising trend is the complementary character between business capitalisation structure and family organisation of business and property.

Therefore, partnership is a business and labour organisation institution that is part of the so-called uses and traditions of fishing activities. It has been maintained and even strengthened in the contemporary context, as a new expression of the "glocal" dynamics that underpin artisanal fisheries. It is an endogenous convention that is already inscribed in traditional cultures, but it also answers external factors such as pressure resulting from new forms of dependence of producers from marketing, financing and equipment agents, imbalance of the sector's labour markets

\footnotetext{
${ }^{17}$ As a system of remuneration (so-called "a la parte"), the total outcomes are considered as a whole to share out between the crew and the ownership (circa 50\%), and for each fishing expedition (weekly or daily, depending on the fishery). In this way, the costs of exploitation are financed by workers as well. Furthermore, "if there is no fishing, there is no "share". A complex system of "shares" and sub-shares separates the crew into several job positions, the skipper being the most important one. There is such a variety of formulas, that it becomes an extraordinarily flexible system; an attribute that, at least in part, explains its high adaptability. As a pattern for the organisation of property, the whole vessel is distributed into several capitalist partners. The skippers and other technical tasks have traditionally been co-owners of vessels, especially in coastal fleets.
}

as a result of the policy of pursuing the dismantling of industry, social security and labour regulations system. It is not necessary to reiterate the functionality of this premodern system in a capitalist model [26,27]; but it is worth mentioning that the partnership system may help us to explain the capacity of response and flexibility of small family businesses in the uncertain environment of economic and political global frame. The apparent paradox then emerges: in a full mercantilisation process of fisheries, old institutions that, according to the conventional economic theory, should be in decline or disappearing are strongly reproducing. This case evidences the peculiar overlapping of artisanal formulas (such as family distribution of property, share system as economic organisation pattern, incorporation of sons to the vessels in technical positions) in business organisations with an increasing level of capitalisation and organisational complexity.

Third, other processes that relate to productive intensification are to be considered [20], like the falling in disuse of other complementary fisheries, increase in the number of fishing expeditions and in the average number of fishing days in a year, recurrence of visits to port to sell catches, new patterns that have been allowed by new sailing and fishing equipments and devices. In Conil, this process can be seen in the progressive allocation of an increasing number of ships to different modalities of gillnets, which ensure indiscriminate catches of species with a greater commercial value such as red mullet, sole or octopus. More and longer gillnets are set as an expression of intensification strategy. All these practices rely on well-defined investment strategies that can be summarised as a specialisation of investments in optimising fishing equipment, both with the incorporation of new mechanical devices on deck and introduction of new and more sophisticated electronic sailing and fish bank detection devices (GPS, electronic navigation maps, sounding devices and sonar). This also includes replacement of current engines by more powerful ones with better performance. In contrast, investment initiatives focusing on joint marketing practices or new and more selective fishing techniques are insignificant.

Finally, the imprint of productive intensification on business organisation schemes and on the perception of fishing resources cannot be overlooked. It is impossible for fishermen to control basic external factors in their favour (such as commercial strategies of great market operators), so their alternative has been an intensification of work and specialisation. At the same time, a more predatory rationale has become widespread, since they assume as an economic objective the achievement of economic returns in a market that they do not control at all and which is underpinned by imbalance between inputs and outputs. The consequence is that new perceptions of natural resources have been incorporated and they are typically from a capitalist economic-cultural system, which is based on a mercantile rationale (resources are assessed in terms of the relationship between cost of exploiting them and price 
1 they intend to get in the sale). Thus, the culture of fishing activities is tragically inserted in the cost/benefit balance typical from modern economic thought.

\subsection{Conflictive aspects in the artisanalisation process}

One of the most relevant aspects in the configuration of the turn of artisanalisation process of Andalusian fisheries is its conflictive character. In those cases in which political-economic limitations have been more threatening since the obstacles to renewal of fishing agreement with Morocco, such as Barbate, there have been capital concentration processes, resulting in fewer companies, overexploitation of resources, workforce proletarisation and more or less latent confrontations between ship owners using different modalities on the one side and between ship owners and sailors on the other.

In labour relations, it is important to analyse the validity of recruitment forms in which being part of the family is a significant factor. The alternatives in social organisation of labour in Andalusian artisanal fleets are still many: ${ }^{18}$ kinship-based relationships, mercantilised relationships and relationships of exploitation of other groups (such as retired, unemployed, youth or more recently immigrants). In short, new forms of exploitation of different social groups have occurred [15].

In Conil, the most urgent problems derive from the activity of illegal fishermen, condemned by professional fishermen both directly and through the administration. However, productive intensification strategies, especially those leading to the adoption of gillnets, may create suspicion among fishermen. The case of Conil, however, is very interesting because its social and labour systems have evolved from the proletarisation of its workforce in industrial fleets and fisheries of other ports to solutions that concentrate capital and labour in the family unit. This therefore entails a reaffirmation of the organisational redeployment around the family. This process, however, goes together with a more or less explicit increase in the exclusion process of fishermen without family links to the group of recently turned ship owners (for instance, the professionalism of fishermen with no family links to owners is questioned). In short, family-based organisations do not imply a lack of social and technical division of labour, which is strong in artisanal businesses even if they have a clear family character and which is expressed in terms of prestige social and responsibility. It is necessary to keep such events in mind in order to prevent reification in organisation schemes defined as artisanal.

\footnotetext{
${ }^{18}$ In [27], a whole theoretical tradition that indicates the replacement and complementary character of kinship-based labour relations with other types of social networks based on friendship or neighbourhood has been collected.
}

\section{Theoretical epilogue as conclusion}

As addressed by FAO in socioeconomic and food security terms, artisanal fisheries are critically important. Application of the term artisanal to fish production processes faces both practical and theoretical challenges. Practical and theoretical because the term is often used by policy makers and industry stakeholders as both a corporative strategy and as a defence against interests of fleets that are technically and socially very different. Furthermore, there is an ideology echoing the potential of this model, which, in order to face socioeconomic and environmental challenges of fisheries in our days, gives a very positive value to the cultural institutions of artisanal fishermen. These institutions include the fishing techniques, forms of territorial appropriation, cooperation/competition relationships between social stakeholders, control and management provisions, values and principles..., what Collet [28] has called the ethic of the sea. Other authors, such as Davis [29], have argued the need for an explicit defence of artisanal groups, especially against bureaucratic and fiscal threats, in the face of the professionalisation required by governments. This is because this professionalisation process has meant that families of fishermen have had to assume rationales that are "foreign" to their local/ vernacular cultures (such as economic calculation for profit accumulation and an extremely competitive individualism), whereas their cultural heritage plays a secondary role, and is even endangered since it is rooted in different organisational rationales (kinship, primary social networks, household economy). Additionally, it has been emphasised how modernisation in fisheries has generated socioeconomic regimes that would be incompatible with core patterns and values in more traditional cultures [4].

The ethnographic cases summarised in this paper, however, can guide us towards other approaches that emphasise the importance of focusing on the interconnection of cultural rationales of artisanal fishermen with socioeconomic trends that make up their context [30]. A broader perspective is therefore required, which sees fishing households and communities as well as political frames and economic contexts (Table 1). It is not just a question of administrative impulses for a more effective management of this type of fleets, but also a question of the processes and tensions resulting from the mercantilisation of a political economy. A qualitative outlook is proposed here, which aims both to search for social, economic and cultural processes lying behind the figures of the sector's macromagnitudes and to analyse the recent situation of the fishing sector that takes into account the arrangement of dynamics at macro-regional and micro-local level. That is, the main task for the researcher would be to understand local situations in the framework of globalisation of fisheries, since fisheries are facing a two-front process of mercantilisation/artisanalisation. Social science cannot remain disengaged from the emerging, the so-called, posttraditional social order, in which the role of tradition has 
1 not disappeared. Rather, the cultural identity, household labour, and capital that are linked to small-scale fleets are helping people to survive in the conflictive context of the increasingly globalised coastal environments. In these locations, recreational, industrial, agricultural and residential activities and uses, particularly linked to tourism, are developed.

This point of view should help us to ask whether it makes sense to continue to define groups and processes as artisanal based solely on endogenous features and on substantive and properly defining cultural institutions, that is, the set of economic and social relations of production that are reproduced in artisanal fisheries that result from a specific economic rationale $[4,8]$. In the current socioeconomic panorama, artisanal fleets have lost some of these features, changed others, and incorporated new institutions (Table 1). Productive specialisation, labour stratification and conflicts, increasing technical and technological component of production processes, growing competition and adoption of complex business accounting are also substantive features, not only of traditionally artisanal fleets, but also of sectors that start from a more industrial model that has experienced a strong artisanalisation process, as evidenced by the work of Breton [31]. Thus, new and traditional artisanal fleets are characterised by the use of attributes that social and cultural theory had conventionally defined as typical from the industrial pattern. At the same time, cultural patterns that fit into the traditional concept of artisanal fleets are preserved, such as labour, political and managerial organisation, or territorial use patterns. This focus should lead us to reflect on the artisanalisation process due to its conflictive articulation into globalisation/localisation processes experienced by contemporary societies. More specifically, it should be understood that "glocalisation" is expressed in fisheries in the mercantilisation/artisanalisation process as two reciprocally feeding processes. As Moran has pointed out, evoking Eric Wolf, what is required is

a research strategy to understand transforming societies needs to be concerned with process, with history, with the role of political and economic power as it influences social relations in time and space at a number of scales from local to global [32, p. 9].

In summary, a relational rather than substantive approach appears to be more suitable, because it accounts not only for the social reproduction capacity of artisanal fleets in the market economy, but also for changes in the dominant model of artisanal fleets in anthropological theory. In order to solve the apparent dilemma affecting artisanal fisheries, that they are either fully inserted into the market or that they will be doomed to a permanent crisis or even to disappearance, it is not enough to acknowledge their cultural heritage and promote institutional management schemes. Given the complexity of the processes involved, it is necessary to act on the market mechanisms, especially on those that underlie wild resources and labour overexploitation processes.

\section{References}

[1] García del Hoyo JJ. El sector pesquero andaluz. Evolución y situación actual. In: Evolución de la producción pesquera andaluza (1985-1999). Sevilla: Consejería de Agricultura y Pesca, Junta de Andalucía; 2001. p. 17-38.

[2] Piniella F, Soriguer MC, Fernández Engo MA. Artisanal fishing in Andalusia: a statistical study of the fleet. Marine Policy 2007;31(4):573-81.

[3] Berkes F, Mahon R, et al. Managing small-scale fisheries. Alternative directions and methods. Ottawa: International Development Research Center; 2001.

[4] Poggie J, Pollnac RB, editors. Small-scale fisheries development: socio-cultural perspectives. Kingston: International Center for Marine Resource Development, University of Rhode Island; 1991.

[5] Van Ginkel R. The dynamics of fisheries: a sensitising framework. In: Symes D, editor. Europe's southern waters. Management issues and practices. Oxford: Blackwell Science; 1999. p. 19-32.

[6] García Canclini N. La globalización imaginada. Buenos Aires: Paidós; 1999.

[7] Robertson R. Globalization: social theory and global culture. London: Sage; 1992.

[8] Freire J, García-Allut A. Socioeconomic and biological causes of management failures in European artisanal fisheries: the case of Galicia (NW Spain). Marine Policy 2000;24(5):375-84.

[9] Garza-Gil MD, Amigo-Dobaño L. The profitability of the artisanal galician fleet. Marine Policy 2007.

[10] Whitmarsh, et al. The economic sustainability of artisanal fisheries: the case of the trawl ban in the Gulf of Castellammare, NW Sicily. Marine Policy 2003;27(6):489-97.

[11] Collet S. The communitarisation of coastal resources or the common ownership of fish resources in Europe: the future for coastal fishing societies in 2002. In: Symes D, editor. Property rights and regulatory systems in fisheries. Oxford: Blackwell Science; 1998. p. 165-74.

[12] Collet S. Regionalisation and eco-development: which pathway for artisanal fisheries? In: Symes D, editor. Europe's southern waters. Management issues and practices. Oxford: Blackwell Science; 1999. p. $42-52$.

[13] Delbos G, Prémel G. The Breton fishing crisis in the 1990s: local society in the throes or enforced change. In: Crean K, Symes D, editors. Fisheries management in crisis. Oxford: Blackwell Science; 1996. p. 129-40.

[14] Symes D. Fishing in troubled waters. In: Crean K, Symes D, editors. Fisheries Management in Crisis. Oxford: Blackwell Science; 1996. p. $3-16$.

[15] Florido del Corral D. Políticas globales y desigualdades locales: efectos socioeconómicos de la política pesquera comunitaria. Revista de Estudios Regionales 2002;62:79-118.

[16] Morata F. La Unión Europea. Procesos, actores y políticas. Barcelona: Ariel; 1999.

[17] Jensen CL. A critical review of the common fisheries policy. IME working paper 6/99, 1999, 〈http://www.sam.sdu.dk/ime/PDF/Jensen6.pdf $>$.

[18] Commission of the European Communities. Green Papers on the future of the Common Fisheries Policy. Brussels; 2001. (II vols. $\operatorname{COM}(2001) 135$ final).

[19] Consejería de Agricultura y Pesca. Plan de actuación para la mejora de la comercialización de los productos de la pesca. Sevilla: Junta de Andalucía. Consejería de Agricultura y Pesca; 2001.

[20] Silva L, Gil J, Sobrino I. Definition of fleet components in the Spanish artisanal fishery of the Gulf of Cádiz (SW Spain ICES division IXa). Fisheries Research 2002;59:117-28.

[21] García-Rodríguez M, Fernández AM, Esteban A. Characterisation, analysis and catch rates of the small-scale fisheries of the Alicante 
1 Gulf (SE Spain) over a 10 years time series. Fisheries Research 2006;77:226-38.

3 [22] García del Hoyo JJ. Análisis bioeconómico y estadístico de pesquerías artesanales andaluzas. Sevilla: Consejería de Agricultura

$5 \quad$ y Pesca, Junta de Andalucía; 2002. Andalucía. Sevilla: Fundación Blas Infante y Consejería de Agricultura y Pesca, Junta de Andalucía; 2002.

[24] Palenzuela P. Las culturas del trabajo: una aproximación antropológica. Sociología Del Trabajo. Nueva Época 1995;24:3-28.

[25] Pálsson G. Technology, practical knowledge and ecological expertise. In: Del Castillo A, editor. Antropología de la Pesca. Debates en el Mediterráneo. Murcia: Universidad de Murcia; 1999. p. 23-31.

[26] Pascual J. The share system in fishing: the case of Canary Island. Europaea 1999;5(2):65-87.

[27] Sánchez JO. Ecología y estrategia social de los pescadores de Cudillero. Madrid: Siglo XXI Editores; 1992.

15 [28] Collet S. From sustainable resource use to governance of marine ecosystems: function and role of the ethic of the sea. In: Symes D, editor. Alternative management systems for fisheries. Oxford: Blackwell Science; 1999. p. 117-26.

[29] Davis A. Insidious rationalities. The institutionalisation of small boat fishing and the rise of the rapacious fisher. Maritime Anthropological Studies 1991;4(1):13-31.

[30] Kurien J. Small-scale fisheries in the context of globalisation: ingredients for a secure future. In: Eide A, Vassdal T, editors. Proceedings of the ninth international conference of the International Institute for Fisheries Economics and Trade. Norway: The Norwegian College of Fishery Science, University of Tromso; 1998, p. $248-59$.

[31] Breton Y. Liens entre pêche industrielle et pêche artisanale. Changements et conséquences pour la recherche. Anthropologie et Sociétés 1994;18(1):93-106.

[32] Moran EF. An agenda for anthropology. In: Moran EF, editor. Transforming societies, transforming anthropology. 4th ed. Ann Arbor: University of Michigan Press; 1999. p. 1-23.

\section{9}

21

23

25

27

29

31

33 